\title{
Estudo de anofelinos antropofílicos peridomiciliares da Praia da Saudade na llha de Cotijuba: uma área endêmica de malária em Belém, Pará
}

\author{
Bento Melo MASCARENHAS ${ }^{1}$, Delma Gomes GUIMARÃES ${ }^{2}$, Manuel Santa BRÍGIDA³ ${ }^{3}$ Claudeth Souza \\ PINTO $^{4}$, Henrique Andrade GOMES NETO 5 , Júlia Daniele Braga PEREIRA 6
}

\begin{abstract}
RESUMO
Apesar da sua localização perto de Belém, Pará, a Ilha de Cotijuba tem sido assolada por surtos de malária durante os últimos anos, principalmente nos meses de abril a maio. A ilha faz parte de um arquipélago situado às margens da baía do Marajó, a $29 \mathrm{~km}$ de Belém, constituindo uma parte insular dessa cidade. Cotijuba possui uma área de cerca de $60 \mathrm{~km}^{2}$ e uma costa com $20 \mathrm{~km}$ de praias, que corresponde a $66 \%$ da área total da ilha. Por causa das repetidas epidemias de malária, nosso interesse voltou-se para conhecer as espécies de anofelinos vetoras. Nos anos de 2002 a 2004 foram realizadas coletas periódicas de mosquitos adultos utilizando-se o método de captura manual com atrativo humano no peridomićlío. Foram realizadas seis coletas bimensais com duração de 6 horas com o registro de apenas duas espécies em atividade atacando o homem, Anopheles (Nyssorhynchus) aquasalis e Anopheles (Anopheles) intermedius. Verificou-se que as condições climáticas, o comportamento dos residentes e a falta de recursos para o efetivo lcontrole dos vetores da doença, favorecem a persistência de malária na Ilha de Cotijuba.
\end{abstract}

PaLAVRaS-CHAVE: Malaria, Anopheles aquasalis, Anopheles intermedius.

\section{Study of peridomiciliares antropofílicos anofelinos of the Beach of the Homesickness in the Island of Cotijuba: an endemic area of malaria in Belém, Pará}

\section{ABSTRACT}

The island of Cotijuba is located at $29 \mathrm{~km}$ of Belém, Pará, Brazil. This island is of approximately $60 \mathrm{~km}^{2}$ and belongs to the Marajó archipelago. Cotijuba has reported repeated outbreaks of malaria during past years, especially in the months of April and May. Due to these outbreaks our interest focused on knowing the anopheline vectors in the island. From 2002 to 2004, periodic mosquito collections were made using human bait at landing and manual capture of resting specimens in the indoors and in the peridomicile. Six bi-monthly collections of 6 hours duration revealed only two man-attracted species: Anopheles (Nyssorhynchus) aquasalis and Anopheles (Anopheles) intermedius. Among other factors, climatic conditions, resident's behavior and lack of resources for control measures contributed to the persistence of malaria in the Island of Cotijuba.

KEY WORDS: Malaria, Anopheles aquasalis, Anopheles intermedius

\footnotetext{
${ }^{1}$ Museu Paraense Emilio Goeldi. Avenida Perimetral 1901- Bairro Terra Firme- Caixa postal 399, Belém-Pará. e-mail: bmelo@museu-goeldi.br

2 Museu Paraense Emilio Goeldi. e-mail: delmabio@yahoo.com.br

3 Museu Paraense Emilio Goeldi. e-mail: santabrigida@yahoo.com.br

${ }^{4}$ Museu Paraense Emilio Goeldi. e-mail: dethsp@yahoo.com.br
} 


\section{INTRODUÇÃO}

No Brasil, a malária concentra-se na região da Amazônia Legal, com mais de 99\% dos casos registrados no país (Brasil, 2004). O estado do Pará é um dos que apresenta maior morbidade por malária. Entre 2001 e 2002 este estado contribuiu com $48 \%$ e $53,5 \%$, respectivamente, do total de casos registrados na Amazônia Legal (SIVEP, 2000-2002). Nos demais estados brasileiros, os casos de malária registrados são quase totalmente importados da Região Amazônica ou de outros países onde ocorre transmissão (SIVEP, 2000-2002).

Em Belém, capital do Pará, 51\% dos 650 casos autóctones de malária notificados nesse município, no ano de 2004, foram procedentes da Ilha de Cotijuba (Renault et. al., 2007). Em Cotijuba desde 1994, o tratamento dos doentes e o controle do vetor fazem parte da rotina do serviço. Entretanto, os números de casos de malária não tiveram diminuição e a maioria das notificações daquela área é de moradores que residem nas proximidades da Praia da Saudade (informação pessoal: dados para o ano de 1996 obtidos na Fundação Nacional de Saúde -FUNASA atuante na Ilha de Cotijuba).

Até a realização deste estudo, nada se conhecia a respeito da fauna anofélica da Ilha de Cotijuba, fato de suma importância uma vez que os casos de malária eram freqüente na região, em especial na praia da Saudade, área turística de intensa visitação durante os finais de semana e feriados. Portanto, o presente estudo se deteve a realizar coletas e identificação das espécies de anofelinos antropofílicos de ocorrência nas proximidades das residências na área da Praia da Saudade - área de malária persistente no estado do Pará - e determinar alguns fatores de risco para a transmissão da doença.

\section{MATERIAL E MÉTODOS}

\section{ÁREA DE ESTUDO}

O Município de Belém compreende uma área de 515.693.000 $\mathrm{m}^{2}$, com 69,46\% (342.520.600 m²) constituídos por um conjunto de 39 ilhas (Silva \& Lobato, 1997). A Ilha de Cotijuba (latitude $01^{\circ} 13^{\prime} 04^{\prime \prime}$ ', longitude $48^{\circ} 32^{\prime} 44^{\prime \prime}$, altitude $10 \mathrm{~m})$ é uma dessas 39 ilhas, está situado à margem direita do estuário do Rio Pará, entre as Baias do Marajó e do Guajará e em frente às Ilhas Jutuba e Paquetá (Figura 1). Ocupa uma área de $16.055 \mathrm{~km}^{2}$, apresentando uma costa com $20 \mathrm{~km} \mathrm{de}$ praias, $12 \mathrm{em}$ seu total, localizadas nos litoral oeste, noroeste e norte da ilha e voltadas para a baía do Marajó, sendo que as mais freqüentadas são as praia do Farol, da Saudade e do Vai Quem Quer. Além das praias a ilha também possui vários lagos e igarapés. Devido aos vários atrativos naturais, a ilha apresenta significativo potencial turístico (Silva \& Lobato, 1997; CODEM, 1997). O número de habitantes apresenta divergências: 637 habitantes (IBGE censo de 1991) e 4.000 (CODEM, 1997; Silva \& Lobato, 1997; Ferreira, 1981).
Cotijuba apresenta uma formação vegetacional diversificada (Almeida \& Mascarenhas, 1998). Existem fragmentos de floresta amazônica de terra firme com graus diferentes de influência antrópica. Em alguns pontos a floresta é alta, densa e possui alguns elementos importantes para a fitogeografia da Amazônia como a árvore emergente Batesia floribunda (acapurana), uma espécie relativamente rara na região e que só ocorre em populações reduzidas e isoladas. Em relação às áreas de floresta secundária, as espécies mais dominantes são: Atallea maripa (inajá), Intanthus sucuuba, (sucuuba), Platonia insignis (bacurí), Ocotea guianensis, Miconia ciliata (chumbinho), Eugenia heterofila, Annona muricata, Swartzia racemosa. As áreas de campina estão caracterizadas por pouca vegetação e associadas ao igapó com água escura e areia branca. É uma área pouco estável de baixa capacidade de recuperação. $\mathrm{O}$ igapó apresenta várias áreas alagadas com água preta caracterizando com isso alto índice de ácido húmico, com um sistema paludoso, dossel irregular e vegetação diversificada como, por exemplo, Euterpe oleracea Mart (açaí), Myrcia sp, Hibiscus sp.

O solo é latossolo amarelo arenoso; há áreas também nos pontos 1' 13' 57'S e 48 32' 58' W com solo arenoso. Nas áreas de várzea o solo é hidromórfico sujeito à lavagem diária, ou seja, pela influência da maré (Almeida \& Mascarenhas, 1998). O clima é tropical chuvoso quente e super-úmido. A precipitação pluviométrica média anual é de $2.800 \mathrm{~mm}$, com período chuvoso de dezembro a junho e um período de estiagem de julho a novembro. A umidade relativa do ar média está em torno de $90 \%$ no período chuvoso e $80 \%$ no período de estiagem. A temperatura oscila entre $24^{\circ} \mathrm{C}$ a $33^{\circ} \mathrm{C}$, com média anual de $26^{\circ} \mathrm{C}$ (Ferreira, 1981).

\section{ESCOLHA DOS PONTOS AMOSTRAIS}

Foram escolhidos três pontos de coletas na área da Praia da Saudade, uma vez que a maioria dos casos de malária era de lá advindo, todos os três ao longo do Igarapé Genipaubinha o qual é composto por um complexo de lagos.

\section{COLETAS}

As coletas foram realizadas nos meses de abril, junho, agosto, outubro e dezembro de 2003 e março de 2004. Em cada mês, realizaram-se três coletas no mesmo dia e em pontos diferentes.

Todas as coletas foram realizadas ao nível do solo, com duração de seis horas (18:00 às 00:00 h), no peridomicílio e com utilização de atrativo humano, com equipe de duas pessoas expondo os membros inferiores e superiores.

Os espécimes foram coletados com auxílio de pequenos tubos de vidros com tampa de borracha, contendo acetato de etila e, separados por intervalo horário. Após as coletas eram transportados e identificados em laboratório. 


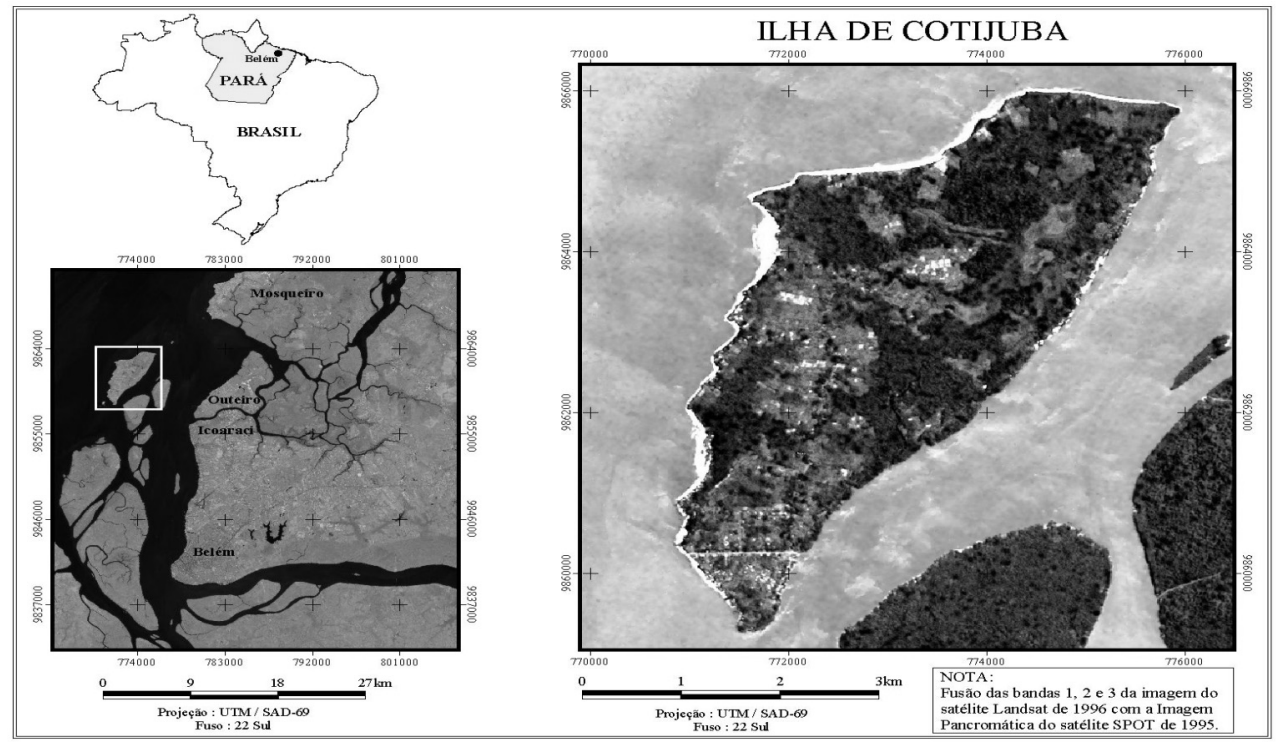

Figura 1- Imagem de Satélite da llha de Cotijuba (cedido pela Unidade de Análises Espaciais do Museu Goeldi - UAE / MPEG).

\section{OBTENÇÃO DOS DADOS CLIMÁTICOS}

Os dados da temperatura máxima e mínima, e da umidade foram obtidos durante a realização das coletas, para cada intervalo. Os dados de pluviosidade foram os presentes em Bastos et al., 2002.

\section{ANÁLISE ESTATÍSTICA}

Utilizou-se o teste de correlação de Spearman (Bioestat 2.0) para analisar os dados climáticos com a atividade dos anofelinos.

\section{RESULTADOS}

\section{COLETA DOS ANOPHELINOS NO PERIDOMICÍLIO}

Foram coletados 169 espécimes pertencentes às espécies: Anopheles (Nyssorhynchus) aquasalis (63,3\%) e Anopheles (Anopheles) intermedius (36,7\%).

An. aquasalis esteve presente em todos os meses de coleta, mantendo uma população mesmo nos meses mais secos. Já o An. intermedius não foi coletado no mês de agosto, um dos meses de menor índice pluviométrico (Figura 2).

Os meses de maior densidade de anofelinos foi abril de 2003 e março de 2004 , com $44,4 \%$ e $26,6 \%$ do total de mosquitos coletados respectivamente, tendo um decréscimo contínuo nos meses de junho e agosto. $\mathrm{O}$ mês de menor densidade foi agosto de 2003 , com apenas $0,6 \%$ dos espécimes capturados, para aumentar novamente nos meses de outubro e dezembro (Figura 3).

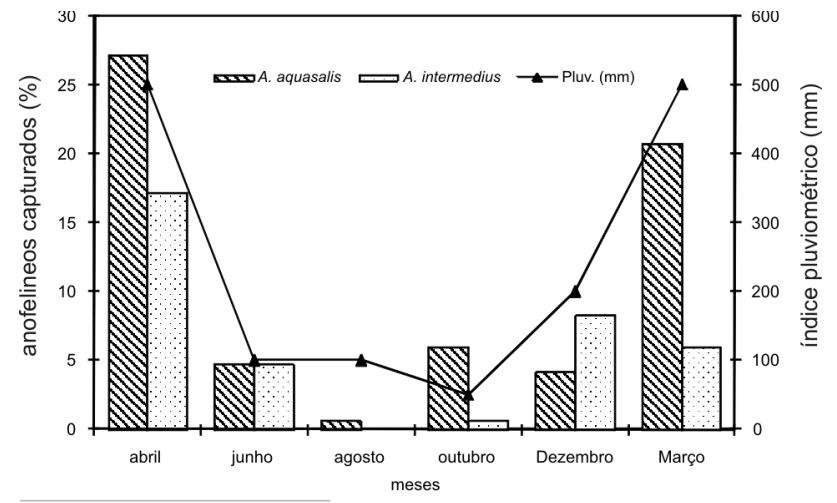

Figura 2 - Frequiência das espécies de Anopheles coletadas entre abril e dezembro de 2003 na Praia da Saudade na llha de Cotijuba, Pará, Brasil.

Uma maior atividade de picar foi observada no intervalo de 19:00 às 20:00h (Figura 4). Foi verificado que a hematofagia no peridomicílio se iniciava a partir das $18: 30 \mathrm{~h}$, quando a luminosidade diminuía. No intervalo das 19:00 às 20:00h a atividade de picar aumentava para logo cair nos intervalos subseqüentes, chegando ao mínimo entre 23:00 e 00:00h.

Foi observado que An. intermedius apresentou dois picos discretos de atividade ham tofágica, um no horário das 18:00 às 19:00h e outro no horário das 20:00 às 21:00h (Figura 5). An. aquasalis apresentou um único pico de atividade entre 19:00 e 20:00h. Neste intervalo horário houve redução na atividade do An. intermedius. É provável que essa alternância de horário de hematofagia seja em função da competição existente entre as duas espécies atuantes na ilha. 


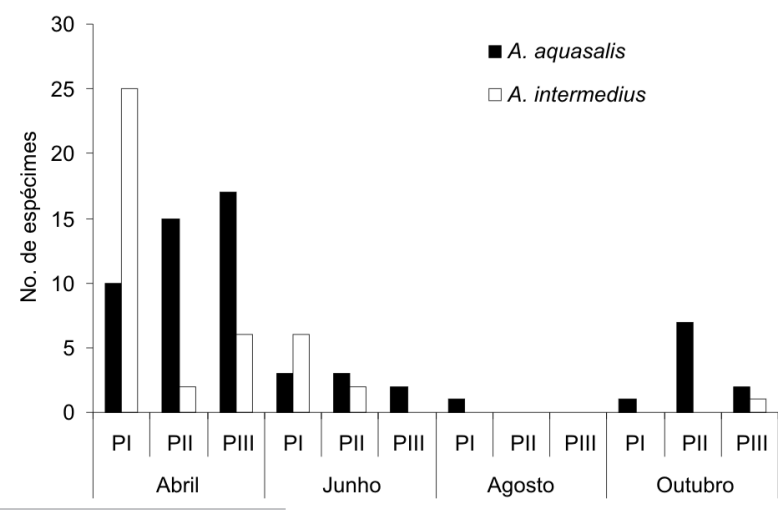

Figura 3 - Anofelinos capturados com atrativo humano no peridomicílio de abril de 2003 a março de 2004 na llha de Cotijuba, Praia da Saudade, pontos I, II e III.

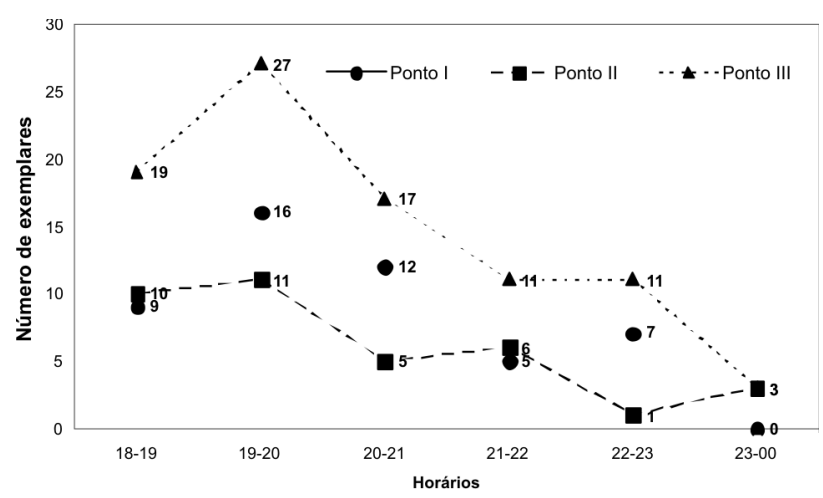

Figura 4 - Atividade horária dos anofelinos no peridomicílio nos pontos I, II e III.

O número de espécimes de mosquitos tendeu à diminuição com aumento da temperatura. Na Ilha de Cotijuba, o mês de outubro foi o mês de maior temperatura enquanto que a maior média de umidade ocorreu nos meses de abril e março e os menores nos meses de agosto e outubro (Figura 6). Os maiores índices pluviométricos ocorreram nos mês de abril e março, coincidindo com aumento da densidade de anofelinos (Figura 7).

Não houve correlação significativa entre atividade de An. intermedius com a temperatura $(\mathrm{p}=0.7489)$, a umidade ( $\mathrm{p}=0.0931)$ e o índice pluviométrico $(\mathrm{p}=0.0931)$. An. aquasalis apresentou correlação significativa entre o aumento de sua densidade em relação a umidade relativa do ar $(\mathrm{p}=0.0307)$ e o índice pluviométrico ( $\mathrm{p}=0.0456)$, não apresentando correlação significativa em relação à temperatura $(\mathrm{p}=0.3552)$.

Durante a realização do trabalho de campo, observou-se que os moradores da Praia da Saudade possuíam hábitos de lavarem roupas no lago Genipaubinha e tomarem banho após as 18:00h, foi observado também, que as pequenas embarcaçōes dos pescadores artesanais ficam ancoradas no

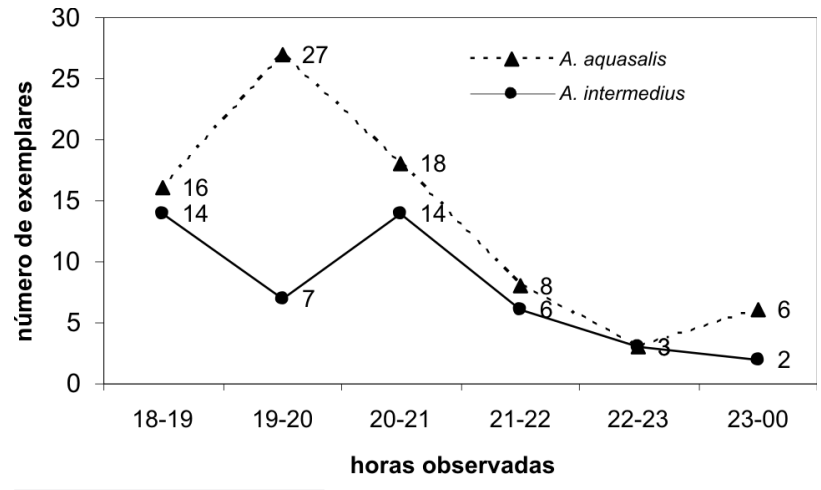

Figura 5 - Atividade horária das duas espécies de anofelinos no peridomicilio.

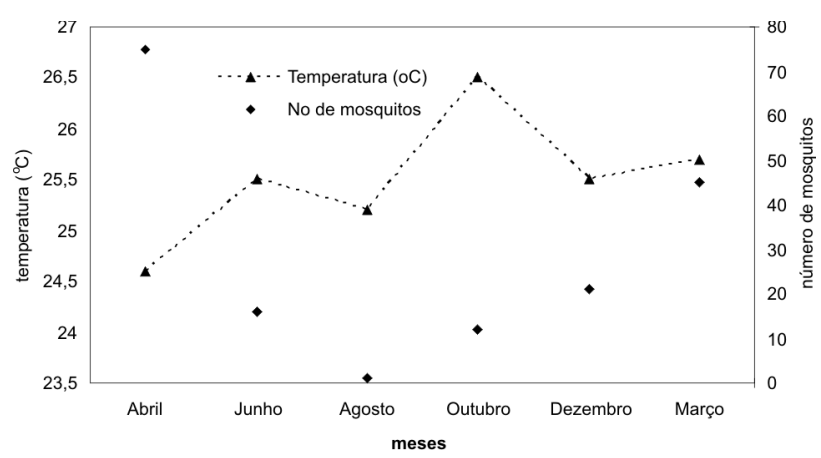

Figura 6 - Comparação da temperatura com o número de anofelinos coletados com atrativo humano no peridomicílio.

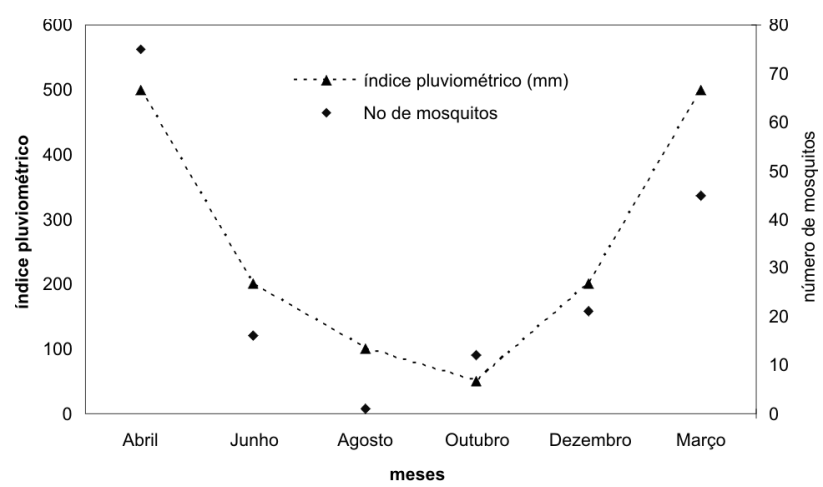

Figura 7 - Comparação do índice pluviométrico com o número de anofelinos coletados com atrativo humano no peridomicílio.

igarapé após seu retorno das pescarias, trata-se de um hábito cultural dos moradores da ilha. É hábito também desses moradores, conversarem do lado externo de suas casas até as 22:00h, assim como ao saírem dos cultos religiosos que encerram-se às 21:00h continuarem suas conversas até altas horas. 


\section{DISCUSSÃO}

A malária que ocorre na Ilha de Cotijuba é produzida por Plasmodium vivax e a maioria dos casos é de origem autóctone (Renaut et. al., 2007). É provável que a ocorrência dessa doença esteja associada às condiçóes favoráveis da área, a qual apresenta hidrografia abundante, proporcionando a manutenção de criadouros para os vetores, assim como os fatores climáticos que são compatíveis para o desenvolvimento do mosquito.

Segundo Forattini (2002) o An. aquasalis apresenta comportamento bastante eclético e sua capacidade vetora diverge nas diversas regiōes de sua ocorrência no Brasil, assumindo o papel de vetor principal da malária, em especial, na região nordeste, devido sua apreciável endofilia e antropofilia e alta densidade em algumas áreas litorânea desta região. De acordo com os achados, na Ilha de Cotijuba, há evidências de que o An. aquasalis seja o principal vetor da malária na ilha e, talvez seja o anofelino que mantém o ciclo da malária na área de estudo, não só por ser o mais prevalente, mas também por conseguir manter suas populaçôes mesmo nos meses mais secos. Isso talvez possa ser explicado devido à dinâmica de seus habitats, que dependem não só das águas das chuvas, mas principalmente das marés, criando um complexo de lagos que funcionam como criatórios potenciais de mosquitos.

Rocha (1996), na Ilha do Marajó, comparou a atividade dos culicídeos com os fatores climáticos e obteve uma relação direta com a umidade e o índice pluviométrico e uma relação inversa com a temperatura e constatou que o mês de abril foi o de maior atividade dos culicídeos. O mesmo foi verificado em nossos estudos em Cotijuba. Comparando-se a presença de anofelinos com a precipitação pluviométrica, verificou-se que a maior prevalência de mosquitos anofelinos se deu no mês de abril.

Segundo Pessoa (1972), fatores como temperatura, umidade e chuvas influenciam de modo decisivo na epidemiologia da malária. A umidade relativa do ar com média mensal inferior a $60 \%$ é desfavorável à transmissão da malária, por encurtar a vida do transmissor e ser nociva ao ciclo do plasmódio. Em temperaturas abaixo de $16^{\circ} \mathrm{C}$ e umidade acima de $35 \%$ a transmissão de malária é dificultada. As chuvas são de importância fundamental para os criadouros de mosquitos. Em nosso estudo observou-se que o endemismo da malária na Ilha de Cotijuba está favorecido às condiçôes oferecidas pelo ambiente vigente na ilha, pois: 1) a umidade relativa do ar nos horários de atividades do mosquito chega perto da saturação; 2) a temperatura média anual fica em torno de $25,5^{\circ} \mathrm{C}$, temperatura esta considerada ótima, tanto para o vetor quanto para o parasita da malária; 3 ) as freqüentes enxurradas nos meses chuvosos, proporcionam a manutenção dos criadouros para os vetores; 4) o comportamento humano de localização das moradias e de exposição nos horários de pico de atividade do anofelinos.

Dos Santos et. al. (2005) em estudo realizado no município de Anajá (Pa) em 2001 e 2002, coletou seis espécies de anofelinos (A. darlingi, A. nuneztovari, A. oswaldoi, A. triannulatus, $A$. albitarsis e $A$. intermedius, esta última com um único exemplar) e verificou que o maior pico de atividade anofélica ocorreu no intervalo horário entre 21:00 e 22:00h. No presente estudo o maior pico de atividades dos anofelinos foi registrada no horário crepuscular de 18:30 às 20:00h. Observou-se que a Comunidade de Cotijuba não possui rede de abastecimento de água e, dentre os hábitos da população, estão o desenvolvimento de atividades básicas de limpeza e hábitos de higiene, como banhos e lavagens de roupas nos igarapés, no final da tarde coincidindo com os horários de maior atividade do mosquito o que pode contribuir para a aquisição e manutenção da malaria nesta ilha.

Outra atividade dos moradores da ilha é a prática de encontros para cultos evangélicos, que ocorrem no horário de pico do Anopheles. Após o termino do culto, normalmente os congregados permanecem à frente da igreja conversando com os amigos e expondo-se às picadas dos mosquitos. Os pescadores também estão mais expostos ao risco de adoecer, uma vez que saem de suas casas para pescar no horário de maior atividade do mosquito.

\section{CONCLUSÕES}

Embora observaçōes mais detalhadas acerca da dinâmica populacional dos mosquitos antropofílicos da Praia da Saudade e do hábito comportamental da população humana local devam ser esmiuçadas, as seguintes conclusões foram obtidas:

Ocorre uma baixa diversidade de espécies na área de estudo.

O horário de maior atividade anofélica no peridomicílio é das 19:00 às 20:00 horas.

$\mathrm{O}$ mês de maior atividade anofélica foi o mês de abril durante o período chuvoso.

As condições climáticas, a hidrografia da ilha, o comportamento dos moradores e a localização das habitações nas bordas das matas de galeria são alguns dos fatores que contribuem para a manutenção da malária na praia da Saudade.

\section{BIBLIOGRAFIA CITADA}

Almeida, S.S.; Mascarenhas, B. M.1998. Relatório Preliminar do Inventário Biológico e do Potencial Ecoturístico da Ilha de Cotijuba, Belém-Pa. Prefeitura Municipal de Belém. Secretaria Municipal de Educação e Cultura Fundação Centro de Referência em 
Educação Ambiental Escola Bosque Prof. "Eidorfe Moreira. Belém - Pará. 33pp.

Bastos, T.X.; Pacheco, N.A.; Nchet, D.; Sá, D.T.A. 2002. Aspectos Climáticos de Belém nos Últimos Cem Anos. Belém: Embrapa Amazônia Orientas, 31pp.

Codem. 1997. Consideraçōes básicas sobre a Elaboração da Proposta do Plano Diretor da Ilha de Cotijuba (Versão preliminar). Prefeitura de Belém. Belém-Pa. 34pp.

Dos Santos, RLC; Sucupira, IMC; Lacerda, RNL; Fayal, AS; Póvoa, MM. 2005. Inquérito entomológico e infectividade durante epidemia de malária no município de Anajás, Estado do Pará. Rev. Soc. Bras. Med. Trop., 38(2): 202-204.

Ferreira, C.P.S. 1981. Hotel Tipo Ecológico como o Equipamento Escola: Pre-Projeto Arquitetônico. Trabalho de Conclusão de Curso,. Universidade Federal do Pará. 1996. 46pp.

Forattini, O.P. 2002. Culicidologia Médica: Identificação, Biologia, Epidemiologia. vol. II. São Paulo. Faculdade de Higiene e Saúde Pública, 860 pp.

IBGE, 1991. Censo demográfico, Região Norte. Disponível em http://www.ibge.gov.br/home/estatistica/populacao/censodem/ default_censo1991.shtm. Acesso em 30/02/2004.

Pessôa B.S. 1972. Parasitologia Médica. $8^{\mathrm{a}}$ ed. Editora Guanabara Koogam, Rio de Janeiro. p. 315 - 319.
Renault, C.S.; Bastos, F.A.; Filgueira, J.P.P.S.; Filgueira, J.P.P.S.; Homma, J.P.P.S. 2007. Epidemiologia da Malária no Município de Belém - Pará. Revista Paraense de Medicina, 21 (3).

Rocha, J.A.M. 1996. Os Mosquitos (Diptera: Culicidae) da Estação Cientifica Ferreira Penna - ECFPn, Caxiuanã, Melgaço, Pará, Brasil: Atividade, Sazonalidade e Estratificação Arbórea. Dissertação de Mestrado. Belém, Museu Paraense Emílio Goeldi/ Universidade Federal do Pará. 129 pp.

Secretaria de Vigilância em Saúde. SIVEP (2000-2002) Sistema de informação em malária. Brasília, 2003.

Secretaria de Vigilância em Saúde/Ms. Saúde Brasil 2004: uma análise da situação de saúde, 2004. Disponível em http://portal. saude.gov.br/portal/arquivos/pdf/capitulo6_sb.pdf. Acessado em 14/09/2007.

Silva, I.D.; Lobato, L. 1997. A. Impactos do Ecoturismo na Belém Insular: Análise Comparativa das Ilhas do Combú e Cotijuba. Universidade Federal do Pará. Núcleo de meio Ambiente. Programa de Formação Interdisciplinar em Meio Ambiente III. $65 \mathrm{pp}$.

Recebido em 29/01/2008

Aceito em 05/03/2009 